\title{
Study on the Pressure Ulcer Care in Home Care Service
}

\author{
Myung-Nam, Lee ${ }^{1}$, Young-Ran, Yeun ${ }^{2 *}$ \\ ${ }^{1,2}$ Department. of Nursing, Kangwon National University, Korea \\ ${ }^{1}$ Mnlee1009@kangwon.ac.kr, ${ }^{2}$ yeunyr@kangwon.ac.kr
}

\begin{abstract}
The purpose of the study was to investigate the relationship between the knowledge of nursing and performance of pressure ulcer in home care service. A total of 129 home care servixe providers were recruited from three home care centers in, Kangwon, Korea. The data were analyzed with descriptive statistics. The knowledge of nursing on pressure ulcer depending on general characteristics had significant difference on education level and attendance at pressure ulcer education within one year. In the performance ulcer, age, education level, working hours per week, and attendance at pressure ulcer education within one year showed significant differences. The knowledge related to pressure ulcer had the positive correlation with the performance $(r=.256, p=.003)$. The results suggested that increasing the education frequency and development of a standardized education system were needed to improve the knowledge and performance of nursing related to pressure ulcer for home care service providers.
\end{abstract}

Keywords: Pressure ulcer, Knowledge, Performance

\section{Introduction}

Due to the rapid increase of the elderly population in Korea, the elderly healthcare has become an important social issue beyond the burden of an individual and the family [1]. In July 2008, Korea introduced an elderly long-term care insurance system separately from the existing health insurance system. This system supports the physical activities and housework of the elderly, who are experiencing difficulties in performing their daily lives by themselves due to aging or geriatric disease, among others [2]. A care service provider plays a key role in operating the elderly long-term care insurance system and provides physical, mental, psychological, emotional, and social care to the beneficiaries of the long-term care insurance, according to the instruction of a doctor or nurse at elderly welfare facilities or home care facilities, among others [3]. In other words, a care service provider is a healthcare professional, who supports not only physical services, but also services required for the elderly, who are experiencing difficulties in performing an independent life due to a geriatric chronic disease, such as dementia or stroke, among others, at the elderly care facilities and home care service facilities. Facility services and home care services include home visit nursing, home visit bath, day and night care, and short-term care, among others. In addition, according to the presence of a disease and physical characteristics, cleaning management, meal and medication assistance, excretion, exercise, emotional support and response, environmental management, and daily life support services, among others, can be provided. A care service provider is also considered as an information deliverer, observer, trained helper, communication subject, and simple daily life support service assistant [4].

Based on the Korean studies regarding the prevalence of diseases in the elderly, who reside at the elderly care facilities, urinary incontinence was $42.2 \%$, pressure ulcer $12.6 \%$, and pneumonia $6.2 \%$, thereby indicating that pressure ulcer is a major heath issue of the elderly who experience difficulty in self-care [5]. A study targeting seniors, who were admitted to a geriatric hospital, reported that pressure ulcer occurred in $38.5 \%$ of the 
elderly [6]. In foreign countries, pressure ulcer has been reported to occur in $18 \%$ of the elderly living in the community [7] and in $6.8 \%$ of the elderly recipients of home nursing services [8]. Pressure ulcer is an important element in elderly health management, and proper preventive nursing care should be provided for the elderly with a high possibility of having pressure ulcer.

Pressure ulcer refers to the necrosis developing in the skin or skin deep tissue due to capillary circulation disorders. It is caused by the interaction in which a continuous and repetitive pressure was applied to a certain site of the body along with friction or shear forces [9]. The first symptom of pressure ulcer is pale-looking skin around the pressure site, then ischemia occurs, and the skin immediately becomes hyperemic after the pressure disappears. Reactive hyperemia is redness caused by blood circulation that immediately increased after the pressure is removed. However, if reactive hyperemia does not disappear, it means the tissue is damaged. In this case, pressure ulcer can only be restored by changing positions. In the second stage, the epidermis, which is a part of the skin, is damaged. If healing is not progressing well during this stage, there is a possibility of infection or contamination through the open wound, or it may lead to deep tissue damage. If the pressure has been relieved during this stage, the skin can be restored within 1-2 weeks. During the third stage, damage and necrosis progress up to the subcutaneous tissue; although, the fascia has not been invaded. Moreover, necrotic tissues must be removed at this stage because it will take several months for a successful recovery. During the fourth stage, tissue necrosis progresses to the muscle, bone, and supporting structure. This stage is characterized by extensive necrosis of the deep tissue that will require a surgical treatment [10].

The elderly are reported to have more than 4 times higher incidence of pressure ulcer, as compared to the general adults, due to many complex factors, such as skin vulnerability, deterioration of the immune system, chronic diseases, malnutrition, muscle strength, and mobility disorders [11]. Pressure ulcer causes pain [12], lowers the quality of life [13], causes infection, such as sepsis and osteomyelitis [14], and increases the elderly mortality approximately 2 times [7].

However, if a pressure ulcer prevention program is applied, the incidence of pressure ulcer can be reduced by $95 \%$ [15]. As the risk factors of pressure ulcer are higher, the incidence of pressure ulcer increases; therefore, assessment on the risk factors must be done as quickly as possible [16]. The risk factors affecting the occurrence of pressure ulcer include age, sex, pressure ulcer history, incontinence, Braden Scale score, malnutrition, body temperature, dehydration, diabetes, diastolic pressure, and edema, among others. [17]. In addition, a higher incidence of pressure ulcer is reported when a patient suffers from a chronic disease, more than one complex diseases, or a more serious disease [18].

To date, the only study regarding pressure ulcer focusing on care service providers in Korea is the study of nursing knowledge and preventive nursing performance on fall and pressure ulcer in care service providers of the elderly care centers [19]. There is no study targeting home care service providers, thus the studies on pressure ulcer prevention and performance of home care service providers are not sufficient. Therefore, this study aims to provide basic data required for preparing nursing intervention on pressure ulcer by investigating the knowledge and performance concerning pressure ulcer in home care service providers. 


\section{Study Methods}

\subsection{Study Design}

This is a descriptive correlation study to investigate pressure ulcer-related knowledge perceived by home care service providers and the degree of pressure ulcer nursing performance in order to identify the correlations between the variables.

\subsection{Study Participants}

This is a descriptive research to investigate the knowledge and performance concerning pressure ulcer in home care service providers. The study subjects include 129 care service providers, who are working at three home care centers located in Gangwon province in Korea. When the sample size was calculated with the effect size of $0.5,85 \%$ statistical power, and a significance level of 0.05 using $G$ power 3.1.2 program, the number of subjects required was 122 persons; therefore, the sample size of this study is appropriate.

\subsection{Study Instruments}

2.3.1. Knowledge Concerning Pressure Ulcer: Knowledge concerning pressure ulcer refers to the overall knowledge, such as the assessment of the pressure ulcer condition related to pressure ulcer nursing, risk factors, prevention, and treatment methods, among others. In order to measure the knowledge concerning pressure ulcer, a pressure ulcer nursing knowledge measurement instrument that was developed by Beitzet, Fey and O'brien, [20] and modified by Jin [21] was used. This instrument consisted of 23 questions in three dimensions, including 4 items on knowledge for the assessment of the pressure ulcer condition, 10 items on knowledge on the risk factors of pressure ulcer, and 9 items on knowledge on pressure ulcer prevention and healing. The score for each item is measured in a binary scale. One point is given for a correct answer, while 0 point is given for a wrong answer. The measurable score ranged from a maximum of 23 points to a minimum of 0 point. A higher score means a higher level of knowledge.

2.3.2. Performance Concerning Pressure Ulcer: Performance concerning pressure ulcer refers to the nursing behaviors related to the assessment and preventive healing of pressure ulcer patients. In order to measure the performance concerning pressure ulcer, the pressure ulcer nursing intervention performance instrument that was developed by Kim [22] and modified by Jin [21] was used. This instrument consisted of 16 items with a 3 -point scale, in which 'always' was given 3 points, 'occasionally' was given 2 points, and 'never' was given 1 point. The score ranged from a maximum of 48 points to a minimum of 16 points. A higher score means a higher level of nursing performance. In the study of Jin [21], Cronbach's $\alpha$ represented the reliability as .83, while in this study, Cronbach's $\alpha$ was .85 .

\subsection{Date Collection Procedure}

For this study, three home care centers located in Gangwon Province were selected via convenience sampling. After the study purpose was explained to the care service providers and their consent to the study participation were obtained, self-administered questionnaires were distributed and the subjects were instructed to fill them out. A total of 150 questionnaires were distributed, and 141 questionnaires were collected. In addition, 129 questionnaires were finally analyzed, while 12 incomplete questionnaires were excluded. 


\subsection{Data Analysis}

The data were analyzed by using the SPSS WIN 18.0 program as follows: The subject's general characteristics were analyzed by calculating the frequency and percentage. The subject's knowledge and performance concerning pressure ulcer were analyzed by calculating the mean and standard deviation. The knowledge and performance concerning pressure ulcer, based on the subject's characteristics, were analyzed by using t-test and ANOVA. In order to identify the relationship between the awareness of pressure ulcer and performance, Pearson's correlation coefficients were obtained.

\section{Results}

\subsection{General Characteristics of the Participants}

Based on the subject's general characteristics, the sex was all female. In terms of age, 68 persons $(52.7 \%)$ were $50-59$ years old, which was the greatest, 41 persons $(31.8 \%)$ were older than 60 years old, 18 persons $(14.0 \%)$ were $30-49$ years old, and 2 persons $(1.6 \%)$ were younger than 30 years old. With regard to the level of education, 47 persons $(36.4 \%)$ were middle school graduates, which was the greatest, 42 persons $(32.6 \%)$ were high school graduates, 33 persons $(25.6 \%)$ were elementary school graduates, 6 persons $(4.7 \%)$ received no education, and one person $(0.8 \%)$ attended junior college or higher. As for working experience, 122 persons $(46.5 \%)$ worked for more than 6 years, which was the greatest, 33 persons $(25.6 \%)$ worked for $4-5$ years, 27 persons $(20.9 \%)$ worked for 1-3 years, and 9 persons (7.0\%) worked less than one year. As for working hours per week, 49 persons $(38.0 \%)$ worked for 30-39 hours, which was the greatest, 44 persons (34.1\%) worked for 20-29 hours, 23 persons (17.8\%) worked more than 40 hours, and 13 persons $(10.1 \%)$ worked less than 20 hours. The number of subjects who participated in education on pressure ulcer management within one year was 97 persons $(75.2 \%)$, which was dominant, and 32 persons $(24.8 \%)$ have never participated in any education on pressure ulcer management (Table 1).

Table 1. General Characteristics of Participants ( $\mathrm{N}=129)$

\begin{tabular}{|l|l|l|}
\hline Characteristics & Categories & $\mathrm{n}(\%)$ \\
\hline Gender & Male & $0(0.0)$ \\
\cline { 2 - 3 } & Female & $129(100.0)$ \\
\hline Age(years) & $<30$ & $2(1.6)$ \\
\cline { 2 - 3 } & $30-49$ & $18(14.0)$ \\
\cline { 2 - 3 } & $50-59$ & $68(52.7)$ \\
\cline { 2 - 3 }$\geq \leq$ & $\geq 60$ & $41(31.8)$ \\
\hline \multirow{5}{*}{$\begin{array}{c}\text { Educational status } \\
\text { Working experience (years) }\end{array}$} & No education & $6(4.7)$ \\
\cline { 2 - 3 } & Elementary school & $33(25.6)$ \\
\cline { 2 - 3 } & Middle school & $47(36.4)$ \\
\cline { 2 - 3 } & High school & $42(32.6)$ \\
\cline { 2 - 3 } & $\geq$ College & $1(0.8)$ \\
\cline { 2 - 3 } & $1-3$ & $9(7.0)$ \\
\cline { 2 - 3 } & $4-5$ & $27(20.9)$ \\
\cline { 2 - 3 } (hours) & $\geq 6$ & $33(25.6)$ \\
\hline \multirow{5}{*}{ Working hours per week } & $<20$ & $60(46.5)$ \\
\cline { 2 - 3 } & $20-29$ & $43(10.1)$ \\
\cline { 2 - 3 } & $30-39$ & $49(34.1)$ \\
\cline { 2 - 3 } & $\geq 40$ & $23(17.8)$ \\
\hline
\end{tabular}




\begin{tabular}{|l|l|l|}
\hline $\begin{array}{l}\text { Attendance at pressure } \\
\text { ulcer education within one } \\
\text { year }\end{array}$ & Yes & $97(75.2)$ \\
\cline { 2 - 3 } & No & $32(24.8)$ \\
\hline
\end{tabular}

\subsection{Knowledge and Performance Levels concerning Pressure Ulcer}

Based on the subject's knowledge concerning pressure ulcer, the score was $11.4 \pm 2.30$ out of 23 points. In terms of the mean score of each dimension, knowledge on pressure ulcer prevention was $2.3 \pm 0.65$ out of 4 points, knowledge on risk factors of pressure ulcer was $4.7 \pm 1.64$ out of 10 points, and knowledge on pressure ulcer healing and prevention was $4.2 \pm 1.33$ out of 9 points. The mean pressure ulcer nursing performance was $33.3 \pm 8.41$ out of 48 points (Table 2 ).

\section{Table 2. The Knowledge and Performance Concerning Pressure Ulcer} $(\mathrm{N}=129)$

\begin{tabular}{|l|l|}
\hline Variables & $\mathrm{M} \pm \mathrm{SD}$ \\
\hline Knowledge & $11.4 \pm 2.30$ \\
\hline Assessment & $2.3 \pm 0.65$ \\
\hline Risk factors & $4.7 \pm 1.64$ \\
\hline Management and prevalence & $4.2 \pm 1.33$ \\
\hline Performance & $33.3 \pm 8.41$ \\
\hline
\end{tabular}

\subsection{Knowledge and Performance Concerning Pressure Ulcer According to General Characteristics}

The knowledge concerning pressure ulcer according to the subject's general characteristics showed statistically significant differences on education level $(\mathrm{F}=6.54$, $p=.000)$ and attendance at pressure ulcer education within one year $(\mathrm{F}=2.03, p=.044)$, but there were no significant differences among age, working experience, and working hours per week. The performance concerning pressure ulcer revealed statistically significant differences on age $(\mathrm{F}=6.61, p=.000)$, education level $(\mathrm{F}=3.92, p=.005)$, working hours per week $(\mathrm{F}=2.16, p=.033)$, and attendance at pressure ulcer education within one year $(\mathrm{F}=2.16, p=.033)$. However, there was no significant difference on working experience (Table 3). In terms of age, the performance concerning pressure ulcer of subjects aged 50 years old and above was significantly higher than that of the subjects aged 30 years old and below.

Table 3. The Knowledge and Performance Concerning of Pressure Ulcer According to General Characteristics ( $N=129)$

\begin{tabular}{|c|c|c|c|c|c|}
\hline \multirow{2}{*}{ Characteristics } & \multirow{2}{*}{ Categories } & \multicolumn{2}{|c|}{ Knowledge } & \multicolumn{2}{|c|}{ performance } \\
\hline & & $\mathrm{M} \pm \mathrm{SD}$ & $\mathrm{F} / \mathrm{t}(p)$ & $\mathrm{M} \pm \mathrm{SD}$ & $\mathrm{F} / \mathrm{t}(p)$ \\
\hline \multirow[t]{4}{*}{ Age(years) } & $<30^{\mathrm{a}}$ & $10.5 \pm 3.56$ & \multirow[t]{4}{*}{$2.53(.060)$} & $19.0 \pm .000$ & \multirow{4}{*}{$\begin{array}{l}6.61(.000) \\
a<c, d\end{array}$} \\
\hline & $30-49^{b}$ & $12.6 \pm 2.50$ & & $27.2 \pm 9.33$ & \\
\hline & $50-59^{c}$ & $11.0 \pm 2.04$ & & $34.4 \pm 7.87$ & \\
\hline & $\geq 60^{\mathrm{d}}$ & $11.5 \pm 2.45$ & & $34.8 \pm 7.42$ & \\
\hline \multirow{5}{*}{$\begin{array}{l}\text { Educational } \\
\text { status }\end{array}$} & No education & $12.6 \pm 2.06$ & \multirow[t]{5}{*}{$6.54(.000)$} & $26.8 \pm 2.04$ & \multirow[t]{5}{*}{$3.92(.005)$} \\
\hline & $\begin{array}{l}\text { Elementary } \\
\text { school }\end{array}$ & $11.5 \pm 2.15$ & & $35.5 \pm 7.45$ & \\
\hline & Middle school & $10.2 \pm 2.08$ & & $34.8 \pm 8.38$ & \\
\hline & High school & $12.3 \pm 2.15$ & & $31.1 \pm 8.57$ & \\
\hline & $\geq$ College & $13.0 \pm 0.00$ & & $16.0 \pm 0.00$ & \\
\hline Working & $<1$ & $10.7 \pm 2.22$ & $0.64(.585)$ & $32.3 \pm 9.81$ & $1.59(.194)$ \\
\hline
\end{tabular}




\begin{tabular}{|c|c|c|c|c|c|}
\hline \multirow{3}{*}{$\begin{array}{l}\text { experience } \\
\text { (years) }\end{array}$} & $1-3$ & $11.4 \pm 2.62$ & & $31.1 \pm 8.92$ & \\
\hline & $4-5$ & $11.0 \pm 2.12$ & & $32.2 \pm 8.54$ & \\
\hline & $\geq 6$ & $11.6 \pm 2.26$ & & $34.9 \pm 7.76$ & \\
\hline \multirow{4}{*}{$\begin{array}{l}\text { Working hours } \\
\text { per week (hours) }\end{array}$} & $<20$ & $11.0 \pm 2.06$ & \multirow[t]{4}{*}{$2.58(.056)$} & $34.6 \pm 9.64$ & \multirow[t]{4}{*}{$2.83(.041)$} \\
\hline & $20-29$ & $10.7 \pm 2.27$ & & $35.0 \pm 7.64$ & \\
\hline & $30-39$ & $12.0 \pm 2.21$ & & $30.6 \pm 9.03$ & \\
\hline & $\geq 40$ & $11.5 \pm 2.40$ & & $35.0 \pm 6.53$ & \\
\hline \multirow{2}{*}{$\begin{array}{l}\text { Attendance at } \\
\text { pressure ulcer } \\
\text { education within } \\
\text { one year }\end{array}$} & Yes & $11.6 \pm 2.33$ & \multirow[t]{2}{*}{$2.03(.044)$} & $34.2 \pm 7.55$ & \multirow[t]{2}{*}{$2.16(.033)$} \\
\hline & No & $10.6 \pm 2.07$ & & $30.5 \pm 10.25$ & \\
\hline
\end{tabular}

\subsection{Correlations between Knowledge and Performance Concerning Pressure Ulcer}

The pressure ulcer-related performance showed a statistically significant positive correlation with the pressure ulcer-related knowledge $(\mathrm{r}=.256, p=.003)$. In particular, it was positively correlated with knowledge on the risk factors of pressure ulcer $(r=.193$, $p=.028)$, and knowledge on pressure ulcer healing and prevention ( $\mathrm{r}=.207, p=.019)$ (Table $4)$.

Table 4. Correlations Between the Knowledge and Performance ( $\mathrm{N}=129)$

\begin{tabular}{|c|l|l|l|l|l|}
\hline & Knowledge & Assessment & $\begin{array}{l}\text { Risk } \\
\text { factors }\end{array}$ & $\begin{array}{l}\text { Management } \\
\text { \& prevalence }\end{array}$ & Performance \\
\cline { 2 - 6 } & $\mathrm{r}(p)$ & $\mathrm{r}(p)$ & $\mathrm{r}(p)$ & $\mathrm{r}(p)$ & $\mathrm{r}(p)$ \\
\hline Knowledge & 1 & & & & \\
\hline Assessment & $.497(.000)$ & 1 & & & \\
\hline Risk factors & $.707(.000)$ & $.091(.305)$ & 1 & & \\
\hline $\begin{array}{l}\text { Management } \\
\text { \& prevalence }\end{array}$ & $.612(.000)$ & $.258(.003)$ & $.055(.534)$ & 1 & \\
\hline Performance & $.256(.003)$ & $.006(.949)$ & $.193(.028)$ & $.207(.019)$ & 1 \\
\hline
\end{tabular}

\section{Discussion}

Pressure ulcer is a preventable and curable skin condition. Care service providers, who are caring for the elderly at risk of pressure ulcer while staying at home, must have professional knowledge on pressure ulcer and perform intervention for its early detection and prevention. This study aimed to investigate the association between knowledge and performance concerning pressure ulcer on home care service providers, and I would like to open a discussion that focuses on it.

In this study, the mean knowledge level concerning pressure ulcer in home care service providers was $11.4 \pm 2.30$ out of 23 points, which was lower than the $24.56 \pm 3.61$ out of 41 points obtained from the study of Yang and Moon [23] that targeted clinical nurses. It was also lower than $0.57 \pm 0.10$ out of 1 point that was obtained from the study of Jo, Kim, and Lee [24] that targeted nurses of care hospitals. Based on the sub-dimensions, knowledge on pressure ulcer prevention was $2.3 \pm 0.65$ out of 4 points, knowledge on the risk factors of pressure ulcer was $4.7 \pm 1.64$ out of 10 points, and knowledge on pressure ulcer healing and prevention was $4.2 \pm 1.33$ out of 9 points. The results indicated that the knowledge on the risk factors of pressure ulcer and knowledge on pressure ulcer healing and prevention were especially low. In terms of individual items, the items with the highest incorrect answer rate were as follows: 'Stage 4 pressure ulcer refers to the damage extending to the epidermis, dermis, and subcutaneous tissue' in the knowledge on the risk factors of pressure ulcer and 'In order to reduce the pressure around pressure ulcer, it is better to use a donut cushion to the skin tissue' in the knowledge on pressure ulcer prevention. For the 
two items, 118 subjects $(91.5 \%)$ gave the wrong answer, which was the highest. It is thought that the reason for the lower knowledge level on pressure ulcer in the subjects of this study, as compared to nurses, is that the opportunity to receive education on pressure ulcer is less, and the awareness of the risk of pressure ulcer is low. In reality, however, patients at a high risk of pressure ulcer, such as patients, including the elderly, with chronic disease, are independently managed by the home care service providers without any cooperation from other healthcare professionals. For this reason, education on pressure ulcer nursing must be enhanced in order to provide them with more knowledge. With regard to the subject's general characteristics, the knowledge on pressure ulcer showed statistically significant differences on education level $(\mathrm{F}=6.54, p=.000)$ and attendance at education on pressure ulcer within one year $(\mathrm{F}=2.03, p=.044)$. Since previous studies on pressure ulcer knowledge on the general characteristics of home care service providers are not sufficient, it is difficult to make a comparison with these study results. However, the result of a previous study [25] reporting that education is an important factor for improving the knowledge on pressure ulcer of health agents was reconfirmed in this study.

The mean performance level of pressure ulcer nursing was $33.3 \pm 8.41$ out of 48 points, which was lower than $3.63 \pm 0.72$ out of 5 points, and $2.52 \pm 0.28$ out of 3 points that were obtained from previous studies $[25,26]$. In terms of individual items, the item 'I use a pressure ulcer risk assessment tool for patients at risk of pressure ulcer' was the lowest, which was $1.41 \pm 0.65$ out of 3 points. The item 'I use the position change table specifically instructed when changing positions of the patients with pressure ulcer or potential patients' was $1.55 \pm 0.79$, and the item 'I do not raise the bed head more than 30 degrees' was $1.68 \pm 0.70$, thereby showing low scores. These are items requiring a considerable amount of professional knowledge, such as the use of a pressure ulcer risk assessment tool or a position change table. Therefore, these results emphasize the need of professional pressure ulcer education for care service providers.

The pressure ulcer risk assessment tool is an instrument to assess the risk of pressure ulcer, and various tools, including Norton, Braden, and Waterlow scales, have been developed. Among them, the Braden scale is the most used tool both domestically and internationally, as it has excellent sensitivity and specificity [27, 28]. The Braden scale consists of six sub-items assessing sense recognition, moisture level, activity level, mobility, nutrition, friction, and shearing forces. Sense recognition is the ability of the patients to express the pressure that is related to discomfort. Moisture level is measured while considering all the secretions of the body that can be associated with humidity as well as incontinence. Activity level is the physical range in which the patients can move, and mobility means the ability of patients to change their position. Nutrition status is the degree of food intake of the patients at an ordinary time, and friction and shearing forces refer to the degree of assistance that is required to avoid slipping when the patients move on the bed [27]. In this instrument, sense recognition, moisture level, activity level, mobility, and nutrition were measured with 1 4 scores, while friction and shearing forces were measured with 1 3 scores. The total score of the 6 sub-items ranges from 6 to 23 points, and a lower total score has a higher incidence of pressure ulcer [27].

A pathological change in the pressure ulcer site is the blood circulation disorder that was caused by a change in the pressure due to a normal weight. The three important factors of the pressure generated when a higher pressure than the normal blood circulation is persistently applied to a certain site of the body, include intensity, time, and pressure [29]. If the intensity of the pressure is high, while pressure is applied for a short time, the tissue can be changed, and if the intensity of the pressure is low, while pressure is applied for a long time, pressure ulcer may occur. Therefore, the most important way to prevent this is through a position change. Typically, patients change their positions as a response to pain; however, the patients may require assistance if they cannot change their positions. The purpose of position change is not only to change the position of a patient, who is 
lying or sitting, but also to improve comfortability by redistributing or reducing the pressure [30].

Among the general characteristics, the variables that showed differences in pressure ulcer nursing performance was age $(\mathrm{F}=6.61, p=.000)$, education level $(\mathrm{F}=3.92, p=.005)$, working hours per week $(\mathrm{F}=2.16, p=.033)$, and attendance at pressure ulcer education within one year $(\mathrm{F}=2.16, p=.033)$. In the previous studies, the pressure ulcer nursing performance was different based on the number of education [23, 24, 31].

Pressure is the most important factor for the development of pressure ulcer. It is transmitted to the bones, which form the skeletal structure underneath the skin, and all tissues between them are pressured. This blocks the flow of the capillary, causes ischemia and hypoxia, and results in pressure ulcer [32]. Shearing force refers to the pressure applied to the buttocks when sitting by a physical force imposed to the given plane and horizontal plane. Friction force refers to the force that appears when two planes move toward different sides. These two forces often act together by peeling the epithelium that was destroyed due to the pressure or causing skin rupture even though they are not the primary causes of pressure ulcer [33]. Pressure ulcer management is important; however, in order to reduce the risks of occurrence of the pressure, shearing force, and friction force, the use of a risk assessment tool or position change is also meaningful. It is believed that provision of education on activities related to them is important.

The pressure ulcer-related performance showed a statistically significant positive correlation with the pressure ulcer-related knowledge $(\mathrm{r}=.256, p=.003)$. This result is opposite to the study result of Jin [21] that targeted nurses in a hospital, in which pressure ulcer nursing knowledge did not show a statistically significant correlation with nursing intervention performance, while the study result of Park [34] and Kim [35] were reported to have a negative correlation. However, it was consistent with the study result of Yang and Moon [23] that was reported to have a positive correlation. The fact that various results have come out with regard to the correlation between pressure ulcer nursing knowledge and pressure ulcer nursing performance implies that other factors may develop between knowledge and performance. It may also mean that the knowledge taught is not performed well at the field. For this reason, further studies need to be performed on home care service providers of various regions in order to clarify the correlation and associated factors. In order to connect the knowledge acquired through education at the actual community field to the performance, a standardized system on assessment of pressure ulcer patients, risk factors, intervention, and prevention must be prepared to continuously provide education to home care service providers. According to the previous papers, the risk factors of pressure ulcer can be classified into internal and external factors. The internal factors include chronic diseases, drugs, age, movement restriction, incontinence, pressure ulcer history, nutrition status, and duration of hospital stay, among others. The external factors include pressure, friction force, and shearing force, among others. Care service providers must perform pressure ulcer nursing intervention by comprehensively understanding the risk factors of pressure ulcer in order to reduce its prevalence and incidence. Recently, with regard to the increase of prevalence and incidence of pressure ulcer, the importance of knowledge on the risk factors of pressure ulcer and nursing performance has been suggested. However, there are still no practical guidelines or assessment tools related to the risk factors of pressure ulcer in Korea, and the hospitals develop their own guidelines or tools to use. Further studies to develop standardized practical guidelines and assessment tools should also be performed in the future.

\section{Conclusion}

Considering that learning and practicing knowledge and skills are important for nursing students, a therapeutic communication simulation scenario development program can be a beneficial option for improving knowledge and skills in nursing students. Our findings 
show the significant effects of a therapeutic communication simulation scenario development program using standardized patients on critical thinking, self-efficacy for learning, and education satisfaction among the nursing students. Future research should investigate and compare the effects of different situations on psychiatric nursing. Additional research is also needed to explore the effects of simulation program on various valuables. It is also recommended that other learning instruments to be used in future studies.

\section{References}

[1] Statistics Korea, e-national statistics, www.kostat.go.kr. (2015).

[2] Ministry of Health \& Welfare, Elderly improved long-term care insurance, http://www.mohw.go.kr/ (2009).

[3] Ministry of Health \& Welfare, Care giver standard textbook, http://www.mohw.go.kr/ (2013).

[4] Ministry of Welfare, 2013 Business conducts guidelines for senior protection agency, http://www.mohw.go.kr/ (2013).

[5] Health Insurance Review \& Assessment Service, Hospital care benefit adequacy assessment, http://www.hira.or.kr/main.do (2009).

[6] M. J. Lee, "Risk Factors of pressure ulcers among elderly in the geriatric hospital," Ewha Womans University, Seoul, (2010).

[7] F. Landi, G. Onder, A. Russo and R. Bernabei, "Pressure ulcer and mortality in frail elderly people living in community," Archives of Gerontology and Geriatrics, vol. 44, (2007), pp. 217-223.

[8] L. Paquay, R. Wouters, T. Defloor, F. Buntinx and L. Geys, "Adherence to pressure ulcer prevention guidelines in home care: a survey of current practice," Journal of Clinical Nursing, vol. 17, no. 5, (2008), pp. 627-636.

[9] National Pressure Ulcer Advisory Panel: "Pressure Injury Stages," http://www.npuap.org/resources/educational-and-clinical-resources/npuap-pressure-injury-stages/ (2016).

[10] G. H. Park and G. S. Kim, "Factors affecting healing of stage 2 pressure ulcer," Journal of Korean Critical Care Nursing, vol. 3, no. 2, (2010), pp. 1-11.

[11] S. Gist, T. I. Matos, S. Falzgraf, S. Cameron and M. Beebe, "Wound care in the geriatric client," Clinical Intervention in Aging, vol. 4, (2009), pp. 269-287.

[12] P. Barbara, L. Diane and C. Janet, "Pressure ulcer pain: a systematic literature review and nationalpressure ulcer advisory panel white paper," Ostomy Wound Management, vol. 55, no. 2, (2009), pp. 56-61.

[13] C. Gorecki, J. M. Brown, E. A. Nelson, M. Briggs, L. Schoonhoven, C. Dealey, T. Defloor, J. Nixon and European Quality of Life Pressure Ulcer Project group, "Impact of pressure ulcers on quality of life in older patients: a systematic review," Journal of the American Geriatrics Society, vol. 57, no. 7, (2009), pp. 1175-1183.

[14] M. D. Fogerty, N. N. Abumrad, L. Nanney, P. G. Arbogast, B. Poulose and A. Barbul, "Risk factors forpressure ulcers in acute care hospitals," Wound Repair and Regeneration, vol. 16, no. 1, (2008), pp. 11-18.

[15] V. Lyman, "Successful heel pressure ulcer prevention program in a long-term care setting," Journal of Wound, Ostomy, and Continence Nursing, vol. 36, no. 6, (2009), pp. 616-621.

[16] J. Riordan and D. Voegeli, "Prevention and treatment of pressure ulcers," British Journal of Nursing, vol. 18 , no. 20, (2009), pp. S20-S27.

[17] M. E. Dellefield, "Prevalence rate of pressure ulcersin California nursing homes: using the OSCAR database to develop a risk adjustment model," Journal of Deontological Nursing, vol. 30, no. 11, (2004), pp. 3-21.

[18] S. D. Horn, S. A. Bender, M. L. Ferguson, R. J. Smout, N. Bergstrom, G. Taler, A. S. Cook, S. S. Sharkey and A. C. Voss, "The National Pressure Ulcer long-term care study: pressure ulcer development in long-term care residents," The American Geriatrics Society, vol. 52, (2004), pp. 359-367.

[19] M. S. Kim, "Care worker's knowledge and implementation for [fall] and pressure ulcers in nursing home for the elderly," Gyeongsang National University, Jinju, (2013).

[20] J. M. Beitz, J. Fey and D. O' Brien, "Perceived need for education vs actual knowledge of pressure ulcer care in a hospital nursing staff," Medical surgical of nursing, vol. 7, no. 5, (1998), pp. 293-301.

[21] I. S. Jin, "Knowledge, performance, and awareness of importance on pressure ulcer care among nurses at a general hospital," Yousei University, Seoul, (2009).

[22] H. Y. Kim, "Knowledge level of pressure ulcer and nursing intervention among hospital nurses," Donga University, Pusan,(2002).

[23] N. Y. Yang and S. Y. Moon, "Perceived importance, educational needs, knowledge and performance concerning pressure ulcer care by clinical nurses," Korean Journal of Adult Nursing, vol. 21, no. 1, (2009), pp. 95-104. 
[24] E. H. Jo, H. S. Kim, and S. J. Lee, "A Study on the knowledge of nurses, performance and preventive practice of pressure ulcer among nurses in long-term care hospital," The Korea Contents Society, vol. 15, no. 8, (2015), pp. 356-365.

[25] E. J. Lee, and S.O. Yang, "Clinical Knowledge and Actual Performance of Pressure Ulcer Care by Hospital Nurses," Journal of Korean Clinical Nursing Research, vol. 17, no. 2, (2011), pp. 251-261.

[26] M. J. Nam, "Nurse's nursing knowledge and nursing performance of pressure sores," Dongshin University, Naju, (2016).

[27] E. A. Ayello and B. Braden, "Why si pressure ulcer risk assessment so important?" Nursing, vol. 35, (2001), pp. 36-45.

[28] Y. H. Lee, I. S. Jung and S. S. Jeun, "A Comparative Study on the Predictive Validity among Pressure Ulcer Risk Assessment Scales," Journal of Korean Academy of Nursing, vol. 33, no.2, (2003), pp. 162169.

[29] R. L. Braddom, "Physical Medicine and Rehabilitation (2nd ed.)," W. B. Saunders, Philadelphia, (2000).

[30] National Pressure Ulcer Advisory Panel, "Prevention and treatment of pressure ulcers: clinical practice guideline," Washington DC, (2009).

[31] M. N. Lee and Y. R. Yeun, "Knowledge and performance concerning pressure ulcer for home care service providers," Asia-pacific Proceedings of Applied Science and Engineering for Better Human Life, vol. 9, (2016), pp. 147-150.

[32] J. Jones, "Evaluation pressure ulcer prevention device: a critical review of the literature," Journal of Wound Care, vol.14, no. 90, (2005), pp. 422-425.

[33] S. Gist, T. I. Matos, S. Falzgraf, S. Cameron and M. Beebe, "Wound care in the geriatric client," Clinical Intervention in Aging, vol. 4, (2009), pp. 269-287.

[34] H. S. Park, K. Y. Park and S. M. Yu, "Factors influencing the development of pressure ulcers in surgical patients," Journal of Korean Academy Nursing, vol.35, no.1, (2005), pp.125-134.

[35] J. H. Kim, "A study on bed sore knowledge, nursing practice of intensive care unit nurse and the occurrence of bed sore," Kwandong University, Gangneung, (2005).

\section{Authors}

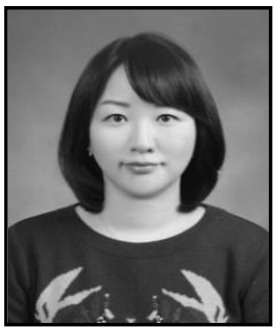

Myung-Nam Lee, She is an assistant professor in the Department of nursing at Kangwon National University. She received her MSN in 2007, and her PhD in nursing in 2014. Her research interests focus on pediatric nursing, nursing education and patient simulation.

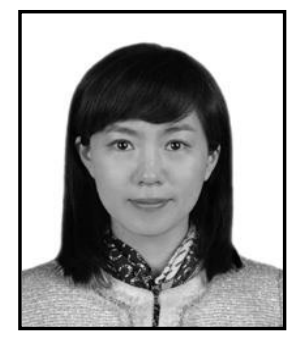

Young Ran Yeun, She is an assistant professor in the Department of nursing at Kangwon National University. She received her MPH in health promotion in 2008, and her $\mathrm{PhD}$ in nursing in 2012. Her research interests focus on identifying psychosocial risk factors for mental problems and promoting mental health. 